Applied Multivariate Research, Volume 13, No. 2, 2010, 161-174

\title{
AN INTERPERSONAL CIRCUMPLEX/FIVE-FACTOR MODEL ANALYSIS OF THE EATING DISORDERS INVENTORY-3
}

\author{
Jeffrey B. Brookings ${ }^{1}$ \\ Wittenberg University \\ Corey D. Beilstein \\ Seed Strategy, Inc.
}

\begin{abstract}
A combined interpersonal circumplex/five-factor model approach was used to investigate personality correlates of Eating Disorders Inventory-3 (EDI-3; Garner, 2004) scales for a non-clinical sample of 234 college women. EDI-3 non-symptom scales and composites had appreciable loadings in the two-dimensional interpersonal circumplex space, with angular locations ranging mainly from Cold $\left(180^{\circ}\right)$ to Submissive $\left(270^{\circ}\right)$. In the five-factor analyses, Neuroticism made significant positive contributions to all of the EDI-3 scales and composites; Conscientiousness made contributions (all negative, save one) to 11 of the 18 scales. The results affirm the centrality of negative affect (i.e., Neuroticism) in disordered eating, but highlight also the importance of assessing interpersonal deficits, which in previous studies have been associated both with the etiology of eating-related problems and increased risk of dropout from treatment. Finally, collapsing or "weighting" EDI-3 item scores may compromise unnecessarily the psychometric properties of the scalesparticularly in non-clinical populations - and we recommend derivation of additional EDI-3 norms, based on unweighted item scores.
\end{abstract}

Keywords: Eating Disorders; Interpersonal Circumplex; Big Five

\section{INTRODUCTION}

The Eating Disorders Inventory (EDI), now in its third edition (EDI-3; Garner, 2004), is a “...self-report measure of psychological traits or constructs shown to be clinically relevant in individuals with eating disorders" (p. 1). The EDI's popularity for clinical assessment and treatment has grown steadily since its publication in 1983 (Theander, 2004), and researchers are increasingly using the EDI to evaluate theoretical models of the structure, antecedents, and consequences of eating disorders. Even though the original EDI was created specifically to evaluate a specific model of anorexia nervosa (Nylander, 1971), its breadth of content (the EDI-3 has 12 scales and 6 composites) makes it attractive to researchers investigating a variety of theoretical perspectives on eating disorders. The EDI-3 composites, for example,

\footnotetext{
${ }^{1}$ Jeffrey B. Brookings, Ph.D., Department of Psychology, Wittenberg University, P.O. Box 720, Springfield, OH 45501, Email: jbrookings@ wittenberg.edu

Note: We thank Stephanie Little for comments on an earlier draft of this article.
} 
assess problems ranging from weight preoccupation to emotional dysregulation to general psychopathology.

Only three of the 12 EDI-3 scales contain eating-related content; the remaining nine scales measure constructs that covary with eating disorders, including personality traits (e.g., low self-esteem, perfectionism). Among these, interpersonally-oriented personality traits have received relatively little attention in eating disorder research, despite evidence linking them to self-reports of disordered eating (e.g., Madison, 1997), and despite the emergence of interpersonal approaches to assessing and treating eating disorders, which view eating-related symptoms as pathological responses to interpersonal problems (Wilfley, Stein, \& Welch, 2005) or as self-regulation failure triggered in part by interpersonal stressors (Horowitz, 2004). The assessment of interpersonal constructs - via patients' self-reports of their interpersonal relationships - may thus fill gaps in the diagnostic picture offered by other approaches (e.g., cognitive-behavioral). In addition, clearer delineation of the interpersonal features of the EDI scales in non-clinical populations may identify interpersonal traits associated with emerging/subclinical eating problems, which occur frequently among college women (Mintz \& Betz, 1988). From its inception, the EDI has included items with interpersonal content, and the most recent version, the EDI-3 (Garner, 2004), includes an Interpersonal Problems Composite. However, the only published study of interpersonal correlates of the EDI among non-patients (Brookings \& Wilson, 1994) used an earlier version of the scale, and the interpersonal scales used in that study precluded fine-grained interpersonal analyses.

\section{The Interpersonal Circumplex}

The interpersonal circumplex has a long research history in clinical assessment (Benjamin, 1996a; Horowitz, 2004; Leary, 1957) and construct validation (Gurtman, 1992; Wiggins \& Broughton, 1985). Briefly, circumplex models of personality view interpersonal traits as blends of two orthogonal, superordinate constructs, Dominance (DOM) and Love (LOV) (Wiggins \& Trapnell, 1996). In numerous studies (see Gurtman \& Pincus, 2003), it has been demonstrated that the pattern of correlations among carefully-constructed interpersonal trait scales conforms closely to a circular or circumplex (Guttman, 1954) ordering about DOM and LOV (see Figure 1), and that the resulting two-dimensional model provides a succinct but comprehensive representation of the interpersonal trait domain. The most visible products of circumplex research are scales for assessing interpersonal traits and problems, including the Interpersonal Adjective Scales (IAS; Wiggins, 1995), the Inventory of Interpersonal Problems-Circumplex (Horowitz, Alden, Wiggins, \& Pincus, 2000), and the Structural Analysis of Social Behavior (Benjamin, 1996b).

Methods for the second application of the interpersonal circumplex, construct validation, were introduced by Wiggins and Broughton (1985) and elaborated subsequently by Gurtman and others (e.g., Gurtman, 1992, 1994; Gurtman \& Pincus, 2003; Tracey, 2000). In this application, measures of target constructs (e.g., eating disorder scales) are evaluated with respect to the extent and quality of their interpersonal content or "interpersonalness" (Gurtman, 1991), estimated from the vector length (extent) and angular placement (quality) of a measured variable - item, scale, composite - in the two-dimensional circumplex space. Vector length reflects a variable's level of "interpersonal saturation" (i.e., longer vector $=$ more interpersonal content), whereas angular placement provides substantive information about the variables' interpersonal content. 
Figure 1. The interpersonal circumplex.

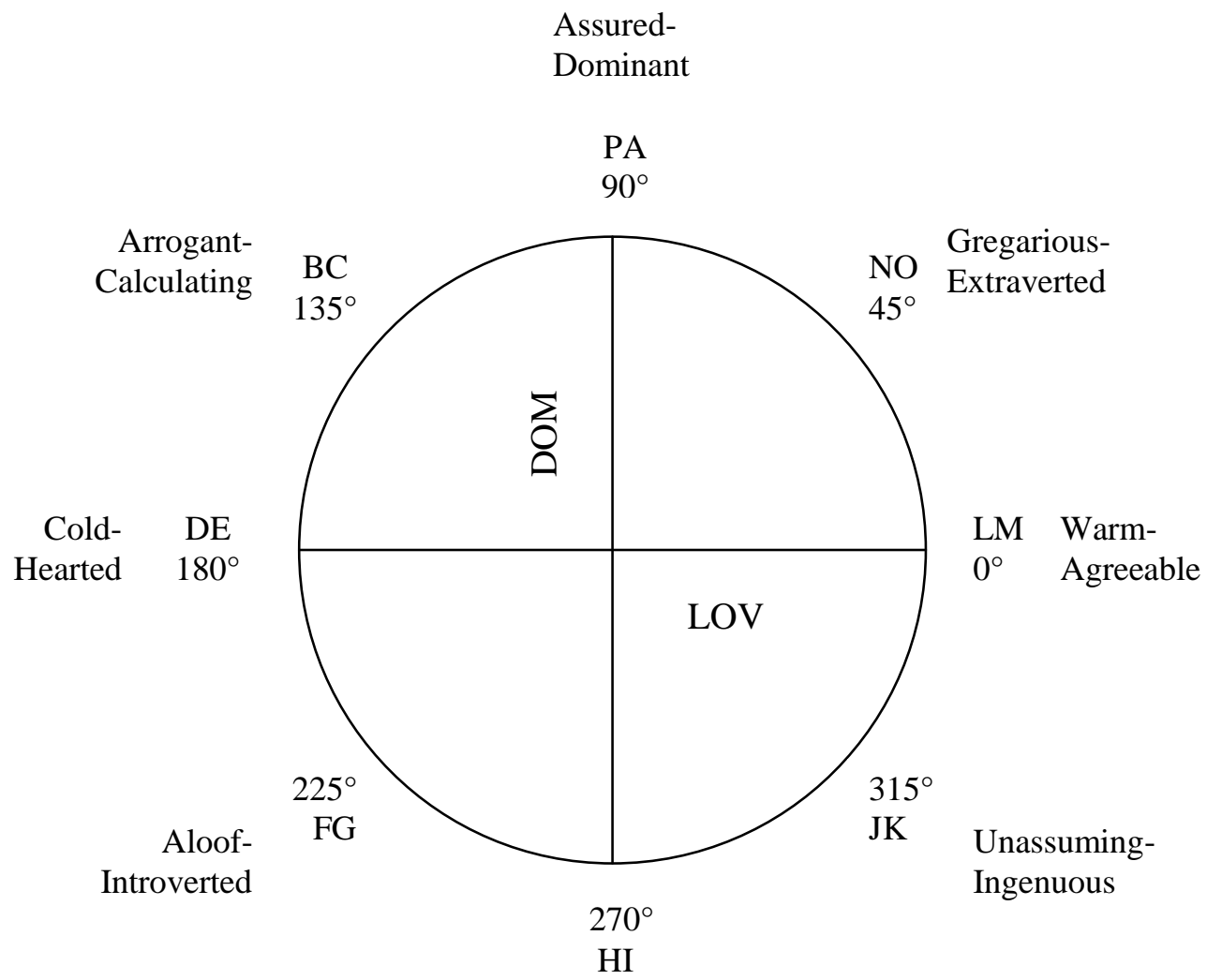

Unassured-

Submissive

The Five-Factor Model of Personality

Factor analytic studies (e.g., McCrae \& Costa, 1989) provide evidence that DOM and LOV are rotational variants of Extraversion and Agreeableness, respectively, the interpersonal dimensions in the five-factor model of personality (McCrae \& John, 1992). Specifically, DOM has been characterized as "cold" Extraversion and LOV as "bold" Agreeableness (Trapnell \& Campbell, 1999). However, the most frequently used interpersonal circumplex measure, Wiggins' (1995) IAS, contains no items assessing the remaining five-factor model traits: Neuroticism, Conscientiousness, and Openness to Experience. To meet the needs of researchers for a combined interpersonal circumplex/fivefactor model measure, Trapnell and Wiggins (1990) added items assessing these three traits to the IAS. The resulting measure, the Interpersonal Adjective Scales Revised-Big Five (IASRB5), was used in this study. 


\section{The Current Research}

In a study of the interpersonal profiles of patients with eating disorders, Madison (1997) identified two prominent subgroups: One had a cold/hostile interpersonal style but the other group was located - surprisingly - in the agreeable/extraverted portion of the circumplex. In a non-clinical sample of female undergraduates (Brookings \& Wilson, 1994), NEO Personality Inventory (NEO-PI; Costa \& McCrae, 1985) Extraversion correlated positively with EDI (Garner \& Olmsted, 1984) Drive for Thinness and negatively with Interpersonal Distrust, and Agreeableness correlated negatively with Ineffectiveness and Interpersonal Distrust. The cross-sectional designs of these studies precluded inferences about the causal priority of interpersonal difficulties and disordered eating. As a practical matter, though, a systematic interpersonal analysis of the EDI could identify scales or combinations of scales with high levels of interpersonal content. These constructs, in turn, could be investigated as risk factors for eating disorders in non-clinical female populations (e.g., college women), for whom "subthreshold" dieting and binging are disturbingly frequent (Kurth, Krahn, Nairn, \& Drewnowski, 1995).

Brookings and Wilson's (1994) interpersonal analyses of the EDI scales were limited by the original NEO-PI, which included only a global measure of Agreeableness (LOV). Also, the recently published EDI-3 (Garner, 2004) reflects - in terms of its scale and composite scale structure - a more distinct interpersonal emphasis than did the original EDI. The objective of this investigation, then, was a combined interpersonal circumplex/five-factor model analysis of the EDI-3 scales and composites for a non-clinical female sample. Based on previous empirical and clinical findings (Brookings \& Wilson, 1994; Madison, 1997; Wilfley, et al., 2005), we predicted that: a) there would be substantial interpersonal loadings for EDI-3 scales and composites related to interpersonal problems and general psychological maladjustment, but not the eating disorder symptom scales (Bulimia, Drive for Thinness, Body Dissatisfaction); b) angular locations for the non-symptom scales would vary widely, reflecting the mixed findings reported in studies of eating disorders and extraversion; and c) across all EDI-3 scales and composites, five-factor model Neuroticism would explain the most unique variance.

\section{METHOD}

\section{Participants}

The participants were 234 female undergraduates at a small Midwestern university, who participated in the study to earn extra credit in introductory psychology courses. The mean age of the women was $20.4(S D=4.2)$.

\section{Measures}

EDI-3. The participants in this study actually completed the EDI-2 (Garner, 1991), as data collection occurred just prior to publication of the EDI-3 (Garner, 2004). However, because the 91 items comprising the EDI-2 and EDI-3 are identical, our participants' responses were scored for both sets of scales. Differences between the two versions are in the number of scales (11 for the EDI-2 and 12 for the EDI-3), minor differences in the allocation of items to the scales and, on the EDI-3, addition of the following six composite scales: Eating Disorder Risk (Drive for Thinness + Bulimia + Body Dissatisfaction); Ineffectiveness (Low Self- 
Esteem + Personal Alienation); Interpersonal Problems (Interpersonal Insecurity + Interpersonal Alienation); Affective Problems (Interoceptive Deficits + Emotional Dysregulation); Overcontrol (Perfectionism + Asceticism); and General Psychological Maladjustment (sum of the nine non-symptom scales).

There is one additional difference, in item scoring: For the EDI-2, the six-point item responses (Always to Never) are "weighted" as follows: Always $=3$, Usually $=2$, Often $=1$; Sometimes, Rarely, and Never are all assigned scores of 0. On the EDI-3, the item weightings are Always $=4$, Usually $=3$, Often $=2$, Sometimes $=1$; Rarely and Never are scored 0. In the EDI-2 manual, Garner (1991) advances a "...rational-theoretical rather than empirical..." (p. 6) justification for weighted item scoring. Specifically, he argued that scores on the nonsymptomatic portion of the continuum should not contribute to total scores on a scale designed to assess psychopathology. There is evidence, however, that the variability lost by truncating item scores compromises the sensitivity of the scales, particularly in non-clinical samples (Schoemaker, Van Strien, \& Van der Staak, 1994; Van Strien \& Ouwens, 2003). To allow comparison of our data with those from other studies, we report descriptive statistics for both the EDI-2 and EDI-3 scales, using weighted and unweighted item scores. The presentation of interpersonal statistics follows the same format. However, to conserve space and simplify the presentation of our findings, circumplex plots and results of the five-factor model multiple regression analyses are presented only for the EDI-3 scales and composites, computed from unweighted item scores.

IASR-B5. The IASR-B5 (Trapnell \& Wiggins, 1990) is a 124-item, interpersonal circumplex/five-factor model measure. The circumplex portion is composed of the 64 items from the IAS (Wiggins, 1995), which are scored for eight octant scales and the orthogonal superordinate constructs DOM and LOV (see Figure 1). To these 64 items, Trapnell and Wiggins (1990) added 20 adjective markers each for Neuroticism, Conscientiousness, and Openness to Experience. Respondents rate how accurately each item describes them on a scale ranging from 1 (Extremely Inaccurate) to 8 (Extremely Accurate). Evidence for the construct validity of the IASR-B5 is summarized by Wiggins and Trobst (2002).

\section{Data Analyses}

Several methods are available to calculate projections of variables in a circumplex space (see Gurtman \& Pincus, 2003), all of which begin with assessment of the extent to which the correlational pattern among the first-order scales (i.e., the IASR-B5 octant scales) conforms to the expected circular ordering. For the analyses reported here, which are based on the vector method described by Wiggins and Broughton (1985, 1991), we then calculated projections of the EDI-3 scales and composites in the two-dimensional circumplex space. This was accomplished using the following formulas: Vector length $(\mathrm{VL})=\left(\mathrm{DOM}^{2}+\right.$ $\left.\mathrm{LOV}^{2}\right)^{1 / 2}$ and angular placement $(\mathrm{AP})=$ arctangent $(\mathrm{DOM} / \mathrm{LOV})$, where DOM and LOV are correlations of the EDI-3 variables with scores on the respective interpersonal constructs. For the five-factor model analyses, simultaneous multiple regression analyses estimated the individual and collective contributions of the five-factor domain scales to each EDI-3 scale and composite. 


\section{RESULTS}

\section{Descriptive Statistics}

Descriptive statistics for the EDI-2 and EDI-3 measures are presented in Table 1. Twelve percent of our sample had EDI-2 Drive for Thinness scores at or above the EDI-2 cutoff for

\section{Table 1}

Descriptive Statistics for the EDI-2 Scales, EDI-3 Scales, and EDI-3 Composites

\begin{tabular}{|c|c|c|c|c|c|c|}
\hline \multirow[b]{2}{*}{ Measure } & \multicolumn{3}{|c|}{ Weighted Scores } & \multicolumn{3}{|c|}{ Unweighted Scores } \\
\hline & M & SD & $\alpha$ & M & SD & $\alpha$ \\
\hline \multicolumn{7}{|l|}{ EDI-2 Scales } \\
\hline Drive for Thinness (7) & 5.2 & 5.8 & .90 & 22.5 & 8.6 & .91 \\
\hline Bulimia (7) & 1.8 & 3.2 & .82 & 15.5 & 6.4 & .86 \\
\hline Body Dissatisfaction (9) & 10.8 & 8.4 & .93 & 34.7 & 11.2 & .92 \\
\hline Ineffectiveness (10) & 2.5 & 3.5 & .80 & 24.6 & 7.8 & .88 \\
\hline Perfectionism (6) & 6.6 & 4.1 & .72 & 22.6 & 5.6 & .75 \\
\hline Interpersonal Distrust (7) & 2.1 & 2.6 & .69 & 17.6 & 5.2 & .77 \\
\hline Interoceptive Awareness (10) & 2.8 & 4.1 & .81 & 25.6 & 7.8 & .86 \\
\hline Maturity Fears (8) & 3.3 & 3.4 & .75 & 23.2 & 6.1 & .81 \\
\hline Asceticism (8) & 3.8 & 2.9 & .52 & 21.8 & 4.9 & .60 \\
\hline Impulse Regulation (11) & 2.2 & 3.5 & .76 & 25.0 & 6.7 & .79 \\
\hline Social Insecurity (8) & 2.7 & 2.6 & .65 & 20.7 & 5.3 & .75 \\
\hline \multicolumn{7}{|l|}{ EDI-3 Scales } \\
\hline Drive for Thinness (7) & 9.5 & 7.7 & .91 & 22.5 & 8.6 & .91 \\
\hline Bulimia (8) & 4.8 & 5.7 & .87 & 17.8 & 7.4 & .89 \\
\hline Body Dissatisfaction (10) & 18.2 & 10.9 & .92 & 37.4 & 11.8 & .92 \\
\hline Low Self-Esteem (6) & 4.1 & 4.3 & .84 & 15.0 & 5.1 & .86 \\
\hline Personal Alienation (7) & 4.8 & 4.4 & .78 & 17.4 & 5.4 & .81 \\
\hline Interpersonal Insecurity (7) & 5.0 & 4.1 & .74 & 18.0 & 5.1 & .78 \\
\hline Interpersonal Alienation (7) & 5.4 & 4.0 & .71 & 17.8 & 4.9 & .74 \\
\hline Interoceptive Deficits (9) & 6.5 & 5.9 & .85 & 23.0 & 7.1 & .86 \\
\hline Emotional Dysregulation (8) & 4.3 & 3.9 & .69 & 17.4 & 5.1 & .73 \\
\hline Perfectionism (6) & 11.2 & 5.0 & .73 & 22.6 & 5.6 & .75 \\
\hline Asceticism (7) & 5.5 & 3.9 & .65 & 17.6 & 5.0 & .68 \\
\hline Maturity Fears (8) & 8.2 & 5.1 & .79 & 23.2 & 6.1 & .81 \\
\hline \multicolumn{7}{|l|}{ EDI-3 Composites } \\
\hline Eating Disorders Risk & 32.7 & 21.4 & .91 & 77.7 & 24.7 & .96 \\
\hline Ineffectiveness & 9.0 & 8.1 & .89 & 32.4 & 10.0 & .91 \\
\hline Interpersonal Problems & 10.5 & 7.0 & .82 & 35.8 & 8.7 & .84 \\
\hline Affective Problems & 10.8 & 8.5 & .86 & 40.4 & 10.6 & .88 \\
\hline Overcontrol & 16.7 & 7.3 & .77 & 40.2 & 8.6 & .79 \\
\hline General Maladjustment & 55.2 & 27.7 & .94 & 172.0 & 34.5 & .95 \\
\hline
\end{tabular}

Note. Weighted item scores for the EDI-2 and EDI-3 range from 0-3 and 0-4, respectively; for both measures, unweighted item scores range from 1-6 (i.e., the original response scale). Alpha coefficients for the EDI-3 composites were estimated using a formula recommended by Nunnally and Bernstein (1994, p. 268). Values in parentheses indicate the number of items on each scale. 
identifying "weight preoccupied" females (Garner, 1991), comparable to the $10 \%$ reported by Garner for a non-clinical college sample. Also, 21\% had EDI-3 Drive for Thinness scores at or above the EDI-3 cutoff, similar to the $22 \%$ in Garner's (2004) non-clinical college sample.

Consistent with findings reported previously for female college students (Van Strien \& Ouwens, 2003), internal consistency reliabilities for EDI-2 scales derived from unweighted item scores were generally higher than their weighted counterparts (median alphas $=.81$ and .76, respectively). The differences in reliabilities were slightly lower for EDI-3 scales computed from the unweighted and weighted item scores (median alphas $=.81$ and .78 , respectively). This was anticipated; as noted earlier, EDI-3 weighted scoring compresses the range for each item from six to five points, whereas EDI-2 weighted scoring truncates the range to four points.

Table 2

Varimax Component Loadings and Interpersonal Statistics for the IASR-B5 Octant Scales

\begin{tabular}{lrrrrr} 
Octant Scale & \multicolumn{2}{c}{ Loadings } & $\begin{array}{r}\text { Vector } \\
\text { Length }\end{array}$ & $\begin{array}{r}\text { Angular } \\
\text { Placement }\left({ }^{\circ}\right)\end{array}$ & $\begin{array}{r}\text { Cosine } \\
\text { Difference }\end{array}$ \\
\hline PA $\left(90^{\circ}\right)$ & .81 & .10 & .82 & 106 & 0.96 \\
BC $\left(135^{\circ}\right)$ & .67 & -.35 & .75 & 140 & 1.00 \\
DE $\left(180^{\circ}\right)$ & .35 & -.76 & .84 & 178 & 1.00 \\
FG $\left(225^{\circ}\right)$ & -.32 & -.82 & .88 & 224 & 1.00 \\
HI $\left(270^{\circ}\right)$ & -.78 & -.37 & .87 & 267 & 1.00 \\
JK $\left(315^{\circ}\right)$ & -.76 & .02 & .76 & 295 & 0.94 \\
LM $\left(360^{\circ} / 0^{\circ}\right)$ & -.47 & .61 & .77 & 345 & 0.97 \\
NO $\left(45^{\circ}\right)$ & .24 & .79 & .82 & 40 & 1.00 \\
$\%$ of Variance & 34.9 & 32.3 & & & \\
\hline
\end{tabular}

PA = Assured-Dominant $; \mathrm{BC}=$ Arrogant-Calculating; $\mathrm{DE}=$ Cold-hearted $; \mathrm{FG}=$ AloofIntroverted; $\mathrm{HI}=$ Unassured-Submissive; $\mathrm{JK}=$ Unassuming-Ingenuous; $\mathrm{LM}=$ WarmAgreeable; $\mathrm{NO}=$ Gregarious-Extraverted. Eigenvalues $=2.8,2.5,0.8,0.6,0.5,0.3,0.2$, and 0.2 .

${ }^{1}$ Correlation between an octant scale's predicted and empirical angular placements after rotating the components to maximum convergence with the theoretical coordinates.

\section{Circumplex Analyses}

Analyses of the IASR-B5, summarized in Table 2, indicate that the pattern of correlations among the octant scales was consistent with geometric assumptions for circularity (Gurtman \& Pincus, 2003). Specifically: a) application of the parallel analysis criterion (Thompson, 2004) to the eigenvalue distribution from a principal components analysis (see bottom of Table 2) was supportive of the expected two-component solution; b) the two components were uncorrelated ( $\mathrm{r}=-.02$; oblimin rotation) and $\mathrm{c}$ ) similar in size; d) the octant scales' vector lengths were comparable; and e) their angular placements-following rotation to maximum convergence (least-squares criterion) -were generally model-consistent, as indicated by the large cosine differences $($ mean $=.98)$. 
Interpersonal statistics for the EDI-2 and EDI-3 measures are displayed in Table 3. Scales with VLs $\geq .30$, a heuristic threshold indicating that a variable has appreciable interpersonal content (Gurtman, 1991), are highlighted in the table and, for the EDI-3, plotted in Figure 2.

Table 3

Interpersonal Statistics for the EDI-2 Scales, EDI-3 Scales, and EDI-3 Composites

\begin{tabular}{|c|c|c|c|c|}
\hline \multirow[b]{2}{*}{ Measure } & \multicolumn{2}{|c|}{ Weighted Scores } & \multicolumn{2}{|c|}{ Unweighted Scores } \\
\hline & VL & AP & VL & AP \\
\hline \multicolumn{5}{|l|}{ EDI-2 Scales } \\
\hline Drive for Thinness & .08 & 303.0 & .06 & 293.8 \\
\hline Bulimia & .04 & 20.8 & .02 & 265.4 \\
\hline Body Dissatisfaction & .11 & 298.4 & .13 & 294.1 \\
\hline Ineffectiveness & .20 & 241.7 & .32 & 245.4 \\
\hline Perfectionism & .19 & 101.4 & .19 & 103.4 \\
\hline Interpersonal Distrust & .36 & 202.7 & .44 & 215.6 \\
\hline Interoceptive Awareness & .11 & 252.5 & .16 & 252.8 \\
\hline Maturity Fears & .15 & 237.2 & .21 & 240.4 \\
\hline Asceticism & .13 & 215.3 & .19 & 220.0 \\
\hline Impulse Regulation & .28 & 167.0 & .30 & 180.0 \\
\hline Social Insecurity & .44 & 223.9 & .53 & 226.8 \\
\hline \multicolumn{5}{|l|}{ EDI-3 Scales } \\
\hline Drive for Thinness & .07 & 295.4 & .06 & 293.8 \\
\hline Bulimia & .05 & 348.3 & .03 & 288.4 \\
\hline Body Dissatisfaction & .12 & 290.7 & .12 & 292.5 \\
\hline Low Self-Esteem & .29 & 252.6 & .33 & 250.7 \\
\hline Personal Alienation & .25 & 233.1 & .30 & 232.7 \\
\hline Interpersonal Insecurity & .54 & 231.1 & .59 & 234.6 \\
\hline Interpersonal Alienation & .38 & 187.8 & .40 & 190.2 \\
\hline Interoceptive Deficits & .14 & 251.4 & .20 & 182.6 \\
\hline Emotional Dysregulation & .32 & 165.0 & .32 & 172.0 \\
\hline Perfectionism & .20 & 103.2 & .19 & 103.4 \\
\hline Asceticism & .16 & 213.4 & .18 & 209.5 \\
\hline Maturity Fears & .18 & 244.4 & .21 & 240.4 \\
\hline \multicolumn{5}{|l|}{ EDI-3 Composites } \\
\hline Eating Disorders Risk & .10 & 299.5 & .09 & 291.9 \\
\hline Ineffectiveness & .28 & 243.4 & .32 & 242.0 \\
\hline Interpersonal Problems & .50 & 213.8 & .53 & 217.3 \\
\hline Affective Problems & .18 & 198.1 & .22 & 206.7 \\
\hline Overcontrol & .13 & 140.2 & .14 & 149.6 \\
\hline General Maladjustment & .29 & 215.5 & .33 & 218.8 \\
\hline
\end{tabular}

Note. VL $($ Vector Length $)=\left(\mathrm{DOM}^{2}+\mathrm{LOV}^{2}\right)^{1 / 2}$ and AP $($ Angular Placement $)=$ arctangent (DOM/LOV), where DOM and LOV are correlations between scores on the EDI "target" variables and the superordinate interpersonal circumplex scales. VLs $\geq .30$ are shown in bold type.

As predicted, none of the VLs for the eating disorder risk scales-Drive for Thinness, Bulimia, Body Dissatisfaction-were $\geq .30$, and the highest VLs were for those scales and composites dealing specifically with interpersonal concerns and problems (e.g., 
interpersonal/social insecurity, interpersonal distrust and alienation). APs for the eight variables with VLs $\geq .30$ ranged from $172^{\circ}$ (DE; Cold-Hearted) to $251^{\circ}$ (HI; UnassuredSubmissive), with an interpersonal "center" in octant FG (Aloof-Introverted). Within this $79^{\circ}$ range, however, there was some variation in angular placement. One EDI interpersonal "mini-cluster," centered on octant scale DE $\left(180^{\circ}\right)$, suggests that interpersonal coldness and hostility are associated with poor affective and behavioral control, particularly in interpersonal situations, and an inability or unwillingness to trust and reach out to others. A second mini-cluster, straddling octant scales FG $\left(225^{\circ}\right)$ and $\mathrm{HI}\left(270^{\circ}\right)$, represents the low-self esteem, social insecurity, and withdrawal that co-occur frequently with eating disorder symptoms. Finally, the EDI-3 composites were located between and roughly equidistant from the two mini-clusters.

Figure 2

Interpersonal circumplex projections for EDI-3 scales and composites with vector lengths $\geq .30$.

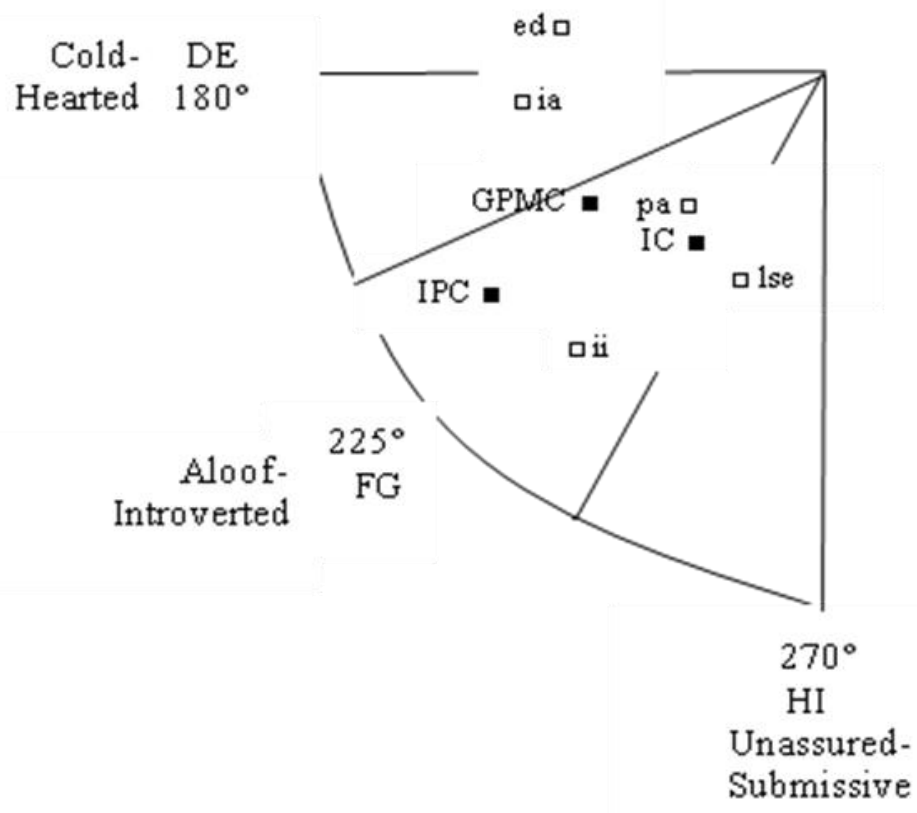

Note. Black squares (घ) are EDI-3 composites: GPMC = General Psychological Maladjustment; IC $=$ Ineffectiveness; IPC $=$ Interpersonal Problems. White squares ( $\square$ ) are scales: ed $=$ Emotional Dysregulation; $\mathrm{ia}=$ Interpersonal Alienation; pa $=$ Personal Alienation; ii = Interpersonal Insecurity; lse = Low Self-Esteem.

Multiple Regression Analyses

Prior to regressing the 18 EDI-3 measures (12 scales +6 composites) on the IASR-B5 five-factor scales, we examined the matrix of zero-order correlations. Neuroticism was 
correlated significantly $(p<.05)$ with all 18 measures, Conscientiousness with 11, DOM and LOV with nine each, and Openness to Experience with two. The correlations of Neuroticism with the EDI-3 measures were all positive, whereas all significant correlations involving the other five-factor scales (except with EDI-3 Perfectionism) were negative. Finally, examination of univariate statistics, bivariate correlations, and standardized residual scatterplots confirmed that the EDI-3 and IASR-B5 data met the assumptions for multiple linear regression (i.e., normally distributed, linearly associated, and homoscedastic).

Results for the simultaneous multiple regression analyses are displayed in Table 4. (Openness to Experience made no significant contributions to the EDI-3 scales and composites and is not included in the table.) As expected, the overall proportions of variance accounted for by the IASR-B5 five-factor scales (i.e., the $R^{2}$ s) were lower for the three eating disorder symptom scales and the Eating Disorders Risk Composite than for the general psychological maladjustment measures. Neuroticism made statistically significant positive contributions to all of the EDI-3 scales and composites and, with one exception, was the only scale that explained significant variance in the three eating disorder symptom scales.

Table 4

Standardized Partial Regression Coefficients and $\mathbf{R}^{2} \mathbf{S}$ for Simultaneous Multiple Regressions of the EDI-3 Scales and Composites on the IASR-B5 Domain Scales

\begin{tabular}{|c|c|c|c|c|c|c|c|c|c|}
\hline \multirow{2}{*}{ Criterion Variables } & \multicolumn{8}{|c|}{ IASR-B5 Domain Scales } & \multirow[b]{2}{*}{$R^{2}$} \\
\hline & \multicolumn{2}{|c|}{ DOM } & \multicolumn{2}{|c|}{ LOV } & \multicolumn{2}{|c|}{$\mathrm{C}$} & \multicolumn{2}{|c|}{$\mathrm{N}$} & \\
\hline \multicolumn{10}{|l|}{ EDI-3 Scales } \\
\hline Drive for Thinness & & & & & & & .399 & $* * *$ & .161 \\
\hline Bulimia & & & & & -.133 & $*$ & .330 & $* * *$ & .123 \\
\hline Body Dissatisfaction & & & & & & & .306 & $* * *$ & .115 \\
\hline Low Self-Esteem & -.217 & $* * *$ & & & -.224 & $* * *$ & .468 & $* * *$ & .365 \\
\hline Personal Alienation & -.145 & * & & & -.229 & $* * *$ & .435 & $* * *$ & .319 \\
\hline Interpersonal Insecurity & -.481 & $* * *$ & -.333 & $* * *$ & & & .160 & ** & .394 \\
\hline Interpersonal Alienation & & & -.358 & $* * *$ & & & .213 & $* *$ & .219 \\
\hline Interoceptive Deficits & & & & & -.146 & $*$ & .433 & $* * *$ & .236 \\
\hline Emotional & & & -.233 & $* * *$ & -.137 & $* *$ & .377 & $* * *$ & .285 \\
\hline \multicolumn{10}{|l|}{ Dysregulation } \\
\hline Perfectionism & & & .161 & $*$ & .122 & $*$ & .384 & $* * *$ & .199 \\
\hline Asceticism & & & & & -.176 & ** & .385 & $* * *$ & .202 \\
\hline Maturity Fears & & & & & -.224 & $* * *$ & .284 & $* * *$ & .171 \\
\hline \multicolumn{10}{|l|}{ EDI-3 Composites } \\
\hline Eating Disorders Risk & & & .125 & $*$ & & & .386 & $* * *$ & .160 \\
\hline Ineffectiveness & -.190 & ** & & & -.239 & $* * *$ & .476 & $* * *$ & .377 \\
\hline Interpersonal Problems & -.340 & $* * *$ & -.396 & $* * *$ & & & .214 & $* * *$ & .343 \\
\hline Affective Problems & & & & & -.176 & $* *$ & .467 & $* * *$ & 292 \\
\hline Overcontrol & & & & & & & .473 & $* * *$ & .235 \\
\hline General Maladjustment & -.148 & * & -.155 & *** & -.168 & $* *$ & .503 & *** & .387 \\
\hline
\end{tabular}

Note. $\mathrm{DOM}=$ Dominance; $\mathrm{LOV}=$ Love $; \mathrm{C}=$ Conscientiousness; $\mathrm{N}=$ Neuroticism. Regression coefficients are shown only for statistically significant predictors $(\mathrm{p}<.05)$. Openness to Experience is omitted because it made no significant unique contributions to the EDI-3 scales and composites. $* p<.05 ; * * p<.01 ; * * * p<.001$. 
Conscientiousness made statistically significant contributions-all negative except for Perfectionism - to seven of the nine psychological maladjustment scales and three composites. As anticipated, DOM and LOV explained the most unique variance in the EDI-3 scales and composites specific to interpersonal problems, and the generally negative regression coefficients for DOM and LOV are consistent with angular placements of the EDI3 measures in the lower left quadrant $\left(180^{\circ}\right.$ to $\left.270^{\circ}\right)$ of the interpersonal circumplex (Figure 2).

\section{DISCUSSION}

The results of this study illustrate the utility of a combined interpersonal circumplex/fivefactor model perspective on the psychometric properties of the EDI-3. The circumplex analyses provided insight into the interpersonal substrate of scales and composites designed to assess broader psychopathological tendencies associated with disordered eating, whereas the five-factor analyses highlighted the contributions of Neuroticism and Conscientiousness to the EDI-3 scales and composites.

The substantial contributions of Neuroticism - across the EDI-3 scales and compositeswere expected. Brookings and Wilson (1994) reported similar results for the original EDI (Garner \& Olmsted, 1984), and current models of eating disorders (e.g., Tylka \& Subich, 2004) emphasize the role of "negative affect" (i.e., neuroticism and low self-esteem) in disordered eating. Conscientiousness explained less unique variance than did Neuroticism, but did make significant (negative) contributions to general psychopathology scales dealing with primarily intrapersonal concerns (e.g., Personal Alienation, Maturity Fears). Finally, and as predicted, DOM and LOV were the largest FFM contributors to the interpersonallyoriented scales (Interpersonal Insecurity, Interpersonal Alienation) and composite (Interpersonal Problems).

In the circumplex analyses, the angular placements of scales with substantial interpersonal loadings were less variable than anticipated. The interpersonal center for these measures was octant FG $\left(225^{\circ}\right)$, but there was evidence as well for two smaller mini-clusters of scales: one reflecting hostility and poor impulse regulation, the other related to low self-esteem, insecurity, and withdrawal from others (see also Madison, 1997). Affect and behavior associated with these interpersonal styles-including depression, loneliness, and social avoidance (Wiggins \& Broughton, 1991) - are in turn associated with interpersonal stressors, which among women with bulimia often precede and may trigger binge eating (Steiger, Gauvin, Jabalpurwala, Seguin, \& Stotland, 1999). In summary, a number of the EDI-3 measures covary with interpersonal deficits (e.g., social isolation, inadequate or impoverished interpersonal relationships) that are central to interpersonal vulnerability models of eating disorders (Wilfley et al., 2005).

As predicted, neither the EDI-3 symptom scales nor the symptom composite had appreciable loadings in the interpersonal circumplex space. One implication of these findings is that interpersonal variables may be useful primarily for predicting satisfaction with and continuation of treatment, rather than direct assessment of eating disorder symptoms per se. This is consistent with recent research suggesting that a) the relationship between interpersonal variables and psychopathology is complex and variable, even within diagnostic categories (Hopwood, Clarke, \& Perez, 2007); and b) "...a targeted interpersonal approach on the part of the therapist has the potential to enhance the alliance and limit treatment dropout" (Ambwani \& Hopwood, 2009, p. 248). 
The principal limitation of this study is its cross-sectional design, which precluded testing hypotheses on the causal priority of interpersonal problems and disordered eating. One suggestion for future research, then, is longitudinal assessment of interpersonal characteristics and eating disorder symptoms. Such studies would enable identification of interpersonal "markers" for subsequent eating disorders, and inform efforts to reduce their incidence. A second limitation of this study is that, because the participants were non-patients, it was not possible to explore possible differences in circumplex projections among the various eating disorder syndromes and subtypes in the DSM-IV (American Psychiatric Association, 1994). Another direction for future research, then, is systematic investigation of the link between interpersonal tendencies and diagnosed eating disorders, starting perhaps with the interpersonal mini-clusters suggested by this study.

Finally, we concur with those investigators (e.g., Schoemaker et al., 1994; Van Strien \& Ouwens, 2003) who conclude that collapsing or "weighting" EDI item scores may compromise unnecessarily the psychometric properties of the scales, particularly in nonclinical populations. Specifically, scales produced by summing weighted item scores had less variability and lower internal consistency reliabilities than did their unweighted counterparts, and in the circumplex analyses, had lower interpersonal loadings as well. To the extent that the interpersonal content in these scales may function as subtle indicators of incipient but subthreshold eating problems in college females, for whom problematic eating behavior is quite common (Kurth et al., 1995; Mintz \& Betz, 1988), restricting the range of item scores seems counterproductive. Accordingly, we recommend derivation of EDI-3 norms based on unweighted item scores as a supplement to the weighted-score norms reported in the EDI-3 manual (Garner, 2004).

In summary, these results confirm that a) negative affect (i.e., Neuroticism) is the largest overall contributor, among five-factor model traits, to the EDI-3 scales and composites; but b) there is a potentially important role as well for interpersonal variables in the assessment of eating disorders. Specifically, the prominent interpersonal features of the EDI-3 scales identified here-interpersonal alienation, insecurity about approaching and confiding in others, and a general reluctance to form close relationships-are those which in previous studies have been associated with the etiology of eating-related problems, as well as with client/therapist relationship problems leading to dissatisfaction with treatment and higher likelihood of dropout.

\section{REFERENCES}

Ambwani, S., \& Hopwood, C. J. (2009). The utility of considering interpersonal problems in the assessment of bulimic features. Eating Behaviors, 10, 247-253.

American Psychiatric Association. (1994). Diagnostic and statistical manual of mental disorders $\left(4^{\text {th }}\right.$ ed.). Washington, DC: Author.

Benjamin, L. S. (1996a). Interpersonal diagnosis and treatment of personality disorders $\left(2^{\text {nd }}\right.$ ed.). New York: Guilford.

Benjamin, L. S. (1996b). A clinician-friendly version of the interpersonal circumplex: Structural Analysis of Social Behavior (SASB). Journal of Personality Assessment, 66, 248-266.

Brookings, J. B., \& Wilson, J. F. (1994). Personality and family-environment predictors of self-reported eating attitudes and behaviors. Journal of Personality Assessment, 63, 313326. 
Garner, D. M., \& Olmsted (1984). Manual for Eating Disorder Inventory. Odessa, FL: Psychological Assessment Resources, Inc.

Garner, D. M. (1991). Eating Disorder Inventory-2 professional manual. Odessa, FL: Psychological Assessment Resources, Inc.

Garner, D. M. (2004). Eating Disorder Inventory-3 professional manual. Lutz, FL: Psychological Assessment Resources, Inc.

Gurtman, M. B. (1991). Evaluating the interpersonalness of personality scales. Personality and Social Psychology Bulletin, 17, 670-677.

Gurtman, M. B. (1992). Construct validity of interpersonal measures: The interpersonal circumplex as a nomological net. Journal of Personality and Social Psychology, 63, 105118.

Gurtman, M. G. (1994). The circumplex as a tool for studying normal and abnormal personality: A methodological primer. In R. Plutchik \& H. R. Conte (Eds.), Circumplex models of personality and emotions (pp. 81-102). Washington, DC: American Psychological Association.

Gurtman, M. B., \& Pincus, A. L. (2003). The circumplex model: Methods and research applications. In J. A. Schinka \& W. F. Velicer (Eds.), Handbook of psychology (Vol. 2): Research methods in psychology (pp. 407-428). New York: Wiley.

Guttman, L. (1954). A new approach to factor analysis: The radex. In P. F. Lazarsfeld (Ed.), Mathematical thinking in the social sciences (pp. 258-348). Glencoe, IL: Free Press.

Hopwood, C. J., Clarke, A. N., \& Perez, M. (2007). Pathoplasticity of bulimic features and interpersonal problems. International Journal of Eating Disorders, 40, 652-658.

Horowitz, L. M. (2004). Interpersonal foundations of psychopathology. Washington, DC: American Psychological Association.

Horowitz, L. M., Alden, L. E., Wiggins, J. S., \& Pincus, A. L. (2000). Manual for the Inventory of Interpersonal Problems. San Antonio, TX: The Psychological Corporation.

Kurth, C. L., Krahn, D. D., Nairn, K., \& Drewnowski, A. (1995). The severity of dieting and bingeing behaviors in college women: Interview validation of survey data. Journal of Psychiatric Research, 29, 211-225.

Leary, T. (1957). Interpersonal diagnosis of personality: A functional theory and methodology for personality evaluation. New York: Ronald Press.

Madison, J. K. (1997). Interpersonal assessment and therapy of eating disorders: A clinical application of a circumplex model. In R. Plutchik \& H. R. Conte (Eds.), Circumplex models of personality and emotions (pp. 431-446). Washington, DC: American Psychological Association.

McCrae, R. R., \& Costa, P. T., Jr. (1989). The structure of interpersonal traits: Wiggins' circumplex and the five-factor model. Journal of Personality and Social Psychology, 56, 586-595.

McCrae, R. R., \& John, O. P. (1992). An introduction to the five-factor model and its applications. Journal of Personality, 60, 175-215.

Mintz, L. B., \& Betz, N. E. (1988). Prevalence and correlates of eating disordered behaviors among undergraduate women. Journal of Counseling Psychology, 35, 463-471.

Nunnally, J. C., \& Bernstein, I. H. (1994). Psychometric theory (3rd ed.). New York: McGraw-Hill.

Nylander, I. (1971). The feeling of being fat and dieting in a school population: An epidemiologic interview investigation. Acta Socio-Medica Scandinavica, 3, 17-26. 
Schoemaker, C, Van Strien, T., \& Van der Staak, C. (1993). Validation of the Eating Disorders Inventory in a nonclinical population using transformed and untransformed responses. International Journal of Eating Disorders, 15, 387-393.

Steiger, H., Gauvin, L., Jabalpurwala, S., Seguin, J. R., \& Stotland, S. (1999). Hypersensitivity to social interactions in bulimic syndromes: Relationship to binge eating. Journal of Consulting and Clinical Psychology, 67, 765-775.

Theander, S. (2004). Trends in the literature on eating disorders over 36 years (1965-2000): Terminology, interpretation, and treatment. European Eating Disorders Review, 12, 4-17.

Thompson, B. (2004). Exploratory and confirmatory factor analysis: Understanding concepts and applications. Washington, DC: American Psychological Association.

Tracey, T. J. G. (2000). Analysis of circumplex models. In H. E. A. Tinsley \& S. Brown (Eds.), Handbook of applied multivariate statistics and mathematical modeling (pp. 641664). San Diego: Academic Press.

Trapnell, P. D., \& Campbell, J. D. (1999). Private self-consciousness and the five-factor model of personality: Distinguishing rumination from reflection. Journal of Personality and Social Psychology, 76, 284-304.

Trapnell, P. D., \& Wiggins, J. S. (1990). Extension of the Interpersonal Adjective Scales to include the big five dimensions of personality. Journal of Personality and Social Psychology, 59, 781-790.

Tylka, T. L., \& Subich, L. M. (2004). Examining a multidimensional model of eating disorder symptomatology among college women. Journal of Counseling Psychology, 51, 314-328.

Van Strien, T., \& Ouwens, M. (2003). Validation of the Dutch EDI-2 in one clinical and two nonclinical populations. European Journal of Psychological Assessment, 19, 66-84.

Wiggins, J. S. (1995). Interpersonal Adjective Scales professional manual. Odessa, FL: Psychological Assessment Resources, Inc.

Wiggins, J. S., \& Broughton, R. (1985). The interpersonal circle: A structural model for the integration of personality research. In R. Hogan \& W. Jones (Eds.), Perspectives in personality (Vol. 1, pp. 1-47). Greenwich, CT: JAI Press.

Wiggins, J. S., \& Trapnell, P. D. (1996). A dyadic-interactional perspective on the five-factor model. In J. S. Wiggins (Ed.), The five-factor model of personality: Theoretical perspectives (pp. 88-162). New York: Guilford.

Wiggins, J. S., \& Trobst, K. K. (2002). The Interpersonal Adjective Scales: Big Five version (IASR-B5). In B. DeRaad \& M. Perugini (Eds.), Big five assessment (pp. 263-280). Seattle: Hogrefe and Huber.

Wilfley, D., Stein, R., \& Welch, R. (2005). Interpersonal psychotherapy. In J. Treasure, U. Schmidt, \& E. van Furth (Eds.), The essential handbook of eating disorders (pp. 137-154). West Sussex, England: Wiley. 